1 Universidade Federal de São Paulo (Unifesp) Santos (SP), Brasil. c_tomanik@yahoo.com

2 Universidade de Brasília (Unb) - Brasília (DF),

Brasil.

vargasdias@hotmail.com

3 Universidade Federal de São Paulo (Unifesp) Santos (SP), Brasil.

mariana.aveiro@unifesp.br

4 Secretaria Municipal de Santos - Santos (SP), Brasil.

anavasconcelos@santos. sp.gov.br

\section{A percepção do usuário sobre a abordagem de uma equipe de residentes multiprofissionais}

\author{
User perception on the approach of a team of multidisciplinary \\ residents \\ Carolina Vieira Tomanik Adolpho', leda Maria Ávila Vargas Dias², Mariana Chaves Aveiro³, Ana \\ Cláudia Freitas de Vasconcelos $\mathbf{4}$
}

RESUMO Estudo qualitativo realizado com o objetivo de identificar e analisar as percepções dos usuários acompanhados por uma equipe de residentes multiprofissional. Os dados foram coletados por meio de entrevistas semiestruturadas, sendo posteriormente submetidos à análise temática que permitiu a construção de três categorias: 1) É diferente, vem com a gente!; 2) Surpresa boa não é aquela que não se espera, é aquela que não se esquece; 3) Críticas: o despertar de potências. A conclusão mostra que aparentemente a abordagem multiprofissional, com tendência interprofissional, vivenciada pelos sujeitos entrevistados envolveu fatores positivos, apesar das barreiras para a efetivação desta prática.

PalaVRas ChaVe Pessoal de saúde; Corpo clínico hospitalar; Integralidade em saúde; Assistência ao paciente; Educação em saúde.

ABSTRACT Qualitative study aiming to identify and analyze the perceptions of users accompanied by a team of Multidisciplinary residents. Data were collected through semi-structured interviews and later submitted to thematic analysis which allowed the construction of three categories: 1) It is different, come along!; 2) a good surprise is not that which is not expected, but that which will not be forgotten; 3) reviews: the awakening of powers. The conclusion shows that apparently the multidisciplinary approach, with inter-professional tendency, experienced by interviewees involved positive factors, despite the barriers to the realization of this practice.

KEYWORDS Health personnel; Medical staff, hospital; Integrality in health; Patient care; Health education. 


\section{Introdução}

Em 2004, na região nordeste do País, foram iniciadas as discussões entre instituições de ensino e o Ministério da Saúde que culminaram na criação das residências multiprofissionais. A motivação surgiu a partir do movimento de implementação de novas diretrizes curriculares para os cursos de saúde, que tiveram como objetivo adequar a formação de profissionais competentes para o Sistema Único de Saúde (SUS). A partir desse processo, as residências multiprofissionais foram criadas com base em uma proposta anteriormente apresentada pelo Departamento de Atenção Básica em 1999. Tal proposta consistiria em programas de formação nos quais fossem preservadas as especialidades de cada profissão envolvida, porém seria criada uma área comum, vinculada aos conceitos de saúde pública, acrescidos de valores, como a promoção da saúde, a integralidade da atenção e o acolhimento (BRASIL, 2006).

Segundo Pinho (2006), entre as décadas de 1970 e 1990, surge e se potencializa o conceito de qualidade em saúde, o qual está intimamente relacionado com a integralidade da assistência. Nesse sentido, a integralidade, um dos princípios do SUS, é definida na Lei 8.080/90.

como um conjunto articulado e contínuo das ações e serviços preventivos e curativos, individuais e coletivos, exigidos para cada caso em todos os níveis de complexidade do sistema. (BRASIL, 1990).

A educação multiprofissional e o trabalho em saúde, desenvolvidos por equipes multiprofissionais, têm sido descritos como instrumentos para efetivar a integralidade no cuidado em saúde. Além disso, as residências multiprofissionais são apontadas como um potente processo formativo que possibilita a construção de um saber coletivo, ampliando as possibilidades do trabalho em equipe e a efetivação de práticas renovadoras (SALVADOR ET AL. 2011).

Ribeiro (2015) traz em sua revisão a reflexão de que no meio profissional é necessário apresentar resolubilidade; para tal, as equipes de trabalho devem organizar suas tarefas. Nesse sentido, o trabalho em equipe integrado tem sido apontado como o mais adequado para atingir melhores resultados, partindo do ponto de que quanto mais mentes se unem para um mesmo propósito, mais soluções satisfatórias tendem a ser desenvolvidas. A autora aponta ainda que o trabalho em equipe na saúde é de maior complexidade por lidar diretamente com vidas e que, então, não se espera algo contábil, matemático ou exato. É um processo que evolui e muda ao longo dos dias, o que o torna altamente dinâmico.

Nesse contexto, Peduzzi (2007) aponta integralidade e interdisciplinaridade como características fundamentais para se trabalhar em equipe de saúde. Tais características se contrapõem ao modelo biomédico e ao trabalho individualizado por profissional, como a integração, a democratização das relações de trabalho e a integralidade e cuidado em saúde.

Para contextualização deste trabalho, torna-se importante que fique clara a diferenciação entre multiprofissional e interprofissional, pois apesar da nomenclatura do programa no qual esta pesquisa foi realizada ser multiprofissional, em seu projeto político-pedagógico consta que as práticas seriam voltadas à forma interprofissional de trabalho. Nesse sentido, a proposta de trabalho desenvolvida consistia na avaliação, no planejamento e na condução dos projetos terapêuticos compartilhados entre os profissionais das várias áreas da saúde que os compõem.

Pesquisando este tema, encontrou-se que a forma multiprofissional de trabalho consiste em diferentes áreas coexistirem lado a lado diante de uma questão, porém sem interação para conduzi-la; enquanto a forma 
interprofissional permite o compartilhar, e não somente complementar o trabalho do outro, existindo troca e ações desenvolvidas em conjunto (FURTADO, 2007).

A forma interprofissional vem com o intuito de combater o atual e intenso processo de especialização profissional (PEDUZZI, 2011). Considerando que a tendência das especialidades é trabalhar de forma fragmentada, na qual o contato com as outras áreas fica restrito a encaminhamentos, que não há construção conjunta de avaliação e elaboração de condutas, a organização interprofissional parece ser mais potente para efetivar a integralidade na atenção à saúde.

Tendo em conta que as atividades desenvolvidas pelos residentes do programa, campo de estudo deste trabalho, se aproximam de uma interprofissionalidade, foi possível vivenciar momentos de troca de saberes entre os profissionais envolvidos. Essa prática tende a promover um atendimento integral para o usuário e, consequentemente, maior resolubilidade devido ao olhar ampliado dessa abordagem.

Ao se tratar de interprofissionalidade, Batista (2012) coloca que a falta de definição precisa; a existência de resistências institucionais docentes e discentes; os embaraços curriculares; as iniciativas simplificadas como estratégia de redução de custos e eventuais problemas com corporações profissionais são obstáculos para implementar programas de formação interprofissional. Apesar das dificuldades descritas, a autora reforça que esse modelo de trabalho em equipe deve ser defendido, pois, além de ser resolúvel, está totalmente relacionado com os princípios e diretrizes do Sistema Único de Saúde (SUS).

Nesse contexto, encontraram-se na literatura estudos e relatos de experiências sobre equipes multiprofissionais, porém, entre estes, pouco se tem sobre a perspectiva do usuário que foi atendido nesse modelo de abordagem. Considerando-se que o usuário é o principal sujeito quando se trata de atenção à saúde, torna-se importante atentar para as percepções deste em relação ao atendimento que recebe. Isso justifica a realização deste estudo, que teve como objetivo identificar e analisar as percepções dos usuários que foram acompanhados por uma equipe de residentes de um programa multiprofissional, nos anos de 2013 e 2014.

\section{Métodos}

O presente estudo trata de uma pesquisa de abordagem qualitativa. Esta abordagem preocupa-se não só com o agir, mas também com o pensar e o interpretar das ações dos seres humanos e da natureza a partir de uma realidade vivida (POLIT; HUNGLER, 2010).

Os dados foram coletados entre julho e dezembro de 2014. O instrumento utilizado foi a entrevista semiestruturada, que combina perguntas abertas e fechadas com o intuito de aprofundar o tema relacionado ao objeto de estudo. Após a assinatura do Termo de Consentimento Livre e Esclarecido, as entrevistas foram gravadas e transcritas integralmente.

As entrevistas foram conduzidas a partir de nove perguntas norteadoras, as quais objetivaram investigar as percepções dos entrevistados sobre trabalho em equipe, as sensações provocadas nos indivíduos a partir da relação com a equipe durante o acompanhamento oferecido, assim como a percepção de diferenças entre a abordagem recebida nesse contexto em relação à que normalmente se encontra em outros serviços de saúde.

Foram estabelecidos como critérios de inclusão: o sujeito ser voluntário, maior de idade e ter sido acompanhado pelas equipes de residentes pelo período mínimo de um mês. O número de sujeitos envolvidos foi determinado pelo ponto de saturação teórica, que significa a repetição das respostas, ou seja, as falas dos sujeitos não apresentarem 
mais nada novo ou diferente do que já tenha sido levantado.

O projeto foi aprovado pelo Comitê de Ética em Pesquisas com Seres Humanos da Universidade Federal de São Paulo com o parecer número 458.275 de acordo com a Resolução 466/2012 do Conselho Nacional de Saúde.

Após a coleta dos dados, estes foram analisados por meio da Análise Temática, que, segundo Minayo (2009), consiste em realizar as transcrições das entrevistas e suas observações, seguida da leitura e releitura delas. A seguir, foi realizada a codificação dessas informações, que consistiu em identificar palavras, frases, temas ou conceitos persistentes, destacando aqueles referentes ao fenômeno. A última etapa foi a categorização dos códigos previamente estabelecidos, na qual os códigos derivados das entrevistas foram agrupados em categorias conforme sua similaridade.

Este trabalho não apresentou conflito de interesses e não recebeu suporte financeiro de nenhuma instituição.

\section{Apresentação e discussão dos resultados}

Esta pesquisa contou com 11 participantes: 9 mulheres e 2 homens. Todos eram usuários ativos do SUS, maiores de 18 anos, com residência na região de abrangência de uma Unidade Básica de Saúde do município de Santos (SP). Esses sujeitos foram acompanhados pelas equipes do Programa de Residência em Atenção à Saúde por mais de um mês entre os anos de 2013 e 2014. Vale ressaltar que a região onde os sujeitos residem é de grande vulnerabilidade social, na qual é comum se deparar com o uso de substâncias ilícitas, além de apresentar altos índices de violência.

A partir da codificação do conteúdo das entrevistas, surgiram três categorias temáticas, a saber: 1) É diferente, vem com a gente!; 2) Surpresa boa não é aquela que não se espera, é aquela que não se esquece; 3 ) Críticas: o despertar de potências. Essas categorias serão descritas a seguir.

\section{É diferente, vem com a gente!}

Para garimpar a percepção dos usuários sobre a atuação em equipe, acreditou-se que seria interessante verificar se os sujeitos percebiam ou não que os profissionais que os atendiam constituíam uma mesma equipe. Nessa questão, a totalidade dos participantes referiu que sim, o que é salutar, pois esse reconhecimento oferece um pertencimento a uma equipe. Além de que, o usuário reconhecer os profissionais da equipe que $o$ atende possibilita a criação de um vínculo que auxilia na adesão e participação de seu cuidado (FRANCO JUNIOR ET AL., 2008).

Algumas falas, inclusive, citavam os nomes dos profissionais que compunham a equipe, mesmo que alguns entrevistados não soubessem dizer qual era a categoria profissional da pessoa. "Uma cuidava da ginástica, que eu não sei o nome da profissão, tem aquela que fez os testes comigo, de sensibilidade do pé" (E8). "É... do negócio de comida, comé que fala? É, elas sempre vinham pergunta né, o negócio das perna, o negócio de bebe água, de bebe, né né... essas coisas". (E9). Ao refletir sobre tais percepções, surgiu o questionamento de que talvez nesse não reconhecimento de categorias profissionais por parte dos usuários entrevistados esteja explicito o resultado de um trabalho interprofissional. Nesse sentido, é relevante retomar que o prefixo inter representa o compartilhar de um mesmo nível de trabalho, de empoderar os colegas de equipe com sua área de conhecimento e, assim, possibilitar a construção conjunta de novos conceitos e práticas (FURTADO, 2007).

A aproximação desse conceito leva ainda a refletir que a prática interprofissional pode permitir também o rompimento de fronteiras interespecíficas apontado por Henz et al. 
(2013). O autor traz que, ao se tratar de processos de formação, promove-se certa baixa da especificidade no cuidado, o que possivelmente tenha dificultado o reconhecimento das profissões por parte dos usuários.

Ainda nessa categoria, nutrição e psicologia foram apontadas em alguns discursos como profissões que surpreenderam os participantes no sentido de mostrar novas vertentes de abordagem profissional. Nesse sentido, o depoimento abaixo mostra satisfação da usuária com a forma de trabalho que lhe foi oferecida pela psicologia, enquanto outras duas apontaram admiração ao descobrir que a nutrição trata de temáticas, como o aleitamento materno, além de ser capaz de oferecer mais do que dietas.

\section{[...] Quando eu comecei com a S., com a A., elas começavam a falar comigo assim coisas do tipo as- sim 'Esse é seu problema, voa mais alto, né? Procu- ra ver que o seu problema não é tão grande assim'. Então ela começou a me fazer, através da psicolo- gia, ter uma visão mais ampla do que realmente éo trabalho do psicólogo. Então foi muito importante, foi muito boa, nessa parte foi muito boa. (E1).}

"A nutrição, eu gosto de nutrição. Eu não sabia que no meio das gestantes assim tinha assim, do aleitamento, entendeu?" (E2). "Nutrição. [...]Ah, ajudar mais do que isso, né?! Aconselhar a comer direito, né?! Sem exagero. Não comer muito sal também nas refeições. Senão a pressão alta, a diabetes e os negócio". (E6).

A julgar pela interação entre profissional e usuário como determinante da qualidade da resposta assistencial, é possível associar que a ampliação do conhecimento dos entrevistados referente às vertentes de atuação de algumas profissões está intimamente relacionada com os princípios da educação em saúde. Além de, consequentemente, favorecer a autonomia dos usuários, pois, a partir do momento que um conceito faz sentido para o indivíduo, ele passa a estar empoderado para tomar decisões pensadas, e não de senso comum (CECCIM, 2014).

O conceito de educação em saúde consiste em um conjunto de saberes e práticas orientadas, visando à prevenção de doenças e à promoção da saúde. Trata-se de um recurso para que o conhecimento cientificamente produzido no campo da saúde, intermediado pelos profissionais de saúde, atinja a realidade das pessoas, uma vez que essa aproximação oferece subsídios para que o indivíduo escolha novos hábitos e condutas de saúde (ALVES, 2012).

Outro dado interessante que compôs essa categoria foi o uso da palavra amizade, apontado na fala de uma participante diante do questionamento de qual seria a diferença percebida pelo usuário no atendimento que lhe foi oferecido pela equipe de residentes e no que normalmente ele encontra em outros serviços de saúde. Este depoimento ilustra o estabelecimento de vínculo, o qual contribui fortemente para a adesão ao cuidado em saúde por parte dos usuários e consequente desenvolvimento de sua autonomia (FRANCO JUNIOR ET AL., 2008). "Ah ela virou a minha amiga sabia? De verdade! Ela me deu a maior força no começo. Acho que de amizade" (E11).

Nesse contexto, vale destacar ainda falas que referiram palavras de forte significação, como realização e humanização. Esses dados possivelmente indicam resultados de dedicação e empenho por parte das equipes, da busca pelo cuidado integral dos usuários e por incentivo a mudanças de um sistema de saúde que precisa transpor o arcabouço teórico e contemplar efetivamente de forma igualitária toda a população.

Realizada! Realizada! Que se não fossem vocês eu não conseguiria chegar ao meu objetivo. Foi fundamental no momento que eu estava passando, porque sem o apoio e o carinho de vocês eu não teria passado pela minha gestação. (E7).

Então vocês trouxeram esse lado do posto, que aqui tem, alguns posto não tem isso não. A pessoa precisa, tá doente, ela precisa de um pouco de atenção. Né?! Quem que não quer carinho? [...] Ah, o lado humano no posto de saúde?! Que a gente não conhecia. Atenção, carinho, mostrar pra eles, mostrar pra gente que a gente precisa 
procurar o médico, que a gente precisa se cuidar, que a gente precisa se tratar. (E8).

Vale destacar que na fala supracitada fica ainda sugerida a preocupação por parte das equipes em empoderar os usuários para que tenham autonomia sobre seu próprio cuidado.

A partir das falas destacadas, foi possível associar as emoções, sensações e percepções expressas nos discursos dos usuários à Política Nacional de Humanização, pois esta apresenta que a escuta qualificada possibilita analisar a demanda e, assim, garantir a atenção integral, aspectos estes que estão embutidos no processo de acolhimento (BRASIL, 2008). Nesse sentido, a aparição da palavra acolhedor no discurso dos usuários indica que tais características podem ter sido encontradas na atenção oferecida.

Nesta análise, surgiram algumas inquietações a partir da reflexão de que para ter sido elaborado um documento que culminasse na construção de uma política pública em defesa da humanização nos serviços de saúde, algum fator motivador disparou tal necessidade. Talvez a ausência dessa característica no campo de trabalho ou ainda a insatisfação dos usuários em relação à atenção que recebem em saúde. Questiona-se então a significação de carinho e acolhimento precisarem ser respaldados por um documento para se tornarem direitos da população.

\section{Surpresa boa não é aquela que não se espera, é aquela que não se esquece}

Com a finalidade de perscrutar mais informações sobre a temática, pensou-se em perguntar se alguma ação realizada pelas equipes que os acompanhavam os surpreendeu. Nesse ponto, surgiram rendosas informações que formaram a categoria em questão.

$\mathrm{Na}$ fala abaixo, é evidenciada a surpresa da participante frente à atenção da equipe voltada para suas dificuldades financeiras que, no desenvolvimento da questão, utilizando uma interessante analogia, mostra que considerou uma prática em saúde o cuidado com suas dívidas e suas dificuldades de organização monetárias.

\begin{abstract}
Mas isso é uma coisa que me surpreendeu... ahh... o interesse de cada um querer ajudar você nas... em várias setores da sua vida né?! Até nisso, né?! Nessa parte financeira, dessa dificuldade que eu tive [...]. É como se fosse uma engrenagem que não está batendo legal, né?! Então se você tem toda uma equipe, que você está tentando, todo mundo tentando ajustar né, para que ela funcione direitinho... a coisa vai funcionar... a sua saúde acaba tendo uma melhora significativa nisso. (E1).
\end{abstract}

Outras participantes se surpreenderam com o fato de os profissionais das equipes que as acompanhavam terem se disposto a acompanhá-las no parto.

Então elas sempre iam lá falar com a minha mãe como que eu estava, ia e voltava. Então assim, isso pra mim foi surpreendente porque eu não imaginava, eu nunca tinha ouvido falar de ninguém assim que ficava. Eu sabia que ficava alguém, mas não imaginava que fosse ficar ali comigo tanto tempo. Não sei se eu dei sorte também, que eu falo assim que às vezes eu acho que eu dei sorte. (E2).

Todo, o aleitamento materno, o fato de vocês tarem me acompanhando psicologicamente, de tarem indo comigo no Naps, ééé... A C. ter ido no meu parto, ter me acompanhado no momento. A C., a A., vocês terem me acompanhado no pré-parto. Terem me acompanhado. (E7).

É possível perceber ainda na fala acima que a surpresa circunda no acompanhamento que lhe foi concedido de forma geral, não só no momento do parto. Um conceito de interessante relação com o acompanhamento é a continuidade do cuidado que, aparentemente, a entrevistada associa à equipe. 
Nesse contexto, Cunha e Giovanella (2011) apontam que uma relação pessoal entre o profissional e o paciente não é uma exigência para garantia do devido acompanhamento, uma vez que bons registros podem suprir a necessidade de informação para tal. Todavia, não é uma realidade em todos os serviços a realização de registros confiáveis que garantam a continuidade do cuidado de seus usuários. Ademais, existem queixas referentes à dificuldade de recursos humanos em unidades de saúde. Tal discussão sugere que seria interessante pensar na realização de registros adequados que assegurem a continuidade do cuidado dos sujeitos, questão esta que está intimamente relacionada com a atenção integral em saúde, que é um direito dos brasileiros segundo a Lei 8.080.

Na fala abaixo, a participante aponta que se surpreendeu a todo o momento, porém notou-se no desenrolar de seu discurso que, aparentemente, o que realmente a surpreendeu foi a mudança gerada a partir da relação que estabeleceu com a equipe. Esse dado fortalece a discussão a despeito da autonomia gerada a partir do vínculo (FRANCO JUNIOR ET AL., 2008).

Todo momento, sabe?! Todo momento. Eu melhorei muito. Eu tô mais feliz, eu tô mais tranquila. Eu tô me, me tratando mais [...] Você me via fazendo essas coisas? Não! Eu aprendi que eu posso viver, que eu posso ser feliz, independente das minhas limitações. Claro, eu faço tudo dentro daquilo que eu posso. Vocês me ensinaram isso. [...] Mas eu não queria. É isso que você não entende, que a gente não qué. Vocês mostraram o caminho pra gente querer. (E8).

Ainda se tratando de ações que surpreenderam os usuários, destaca-se a comemoração com bolo e parabéns em seus aniversários. Entretanto, é importante ressaltar que, referente a essa ação, um participante aponta no decorrer de sua fala que não a considerou como uma ação em saúde.

A minha maió alegria desse mês, que nem meus filho, nem minha ex-mulher, nem meus neto, não representaram nada. Sabe qual foi? Setenta e sete primavera. Meu aniversário. E elas... E essas menina trouxeram um bolo. Trouxeram refrigerante de acerola e cantaram parabéns pra mim [emocionado]. Não, me surpreendi porque foi uma coisa nova né?! [...] Eu gostava do atendimento, o, o, do preparo delas. Não, porque atendimento mesmo eu não vi nenhum. [...] Atendimento mesmo eu num vi. [...] Porque esse negócio que eu te falei do parabéns... Isso eu acho que não é uma ação em saúde, mas eu fiquei satisfeito porque foi uma alegria que me deu. (E3).

Elas até vieram cantar parabéns pra mim! Essa me surpreendeu! Acredite-me mesmo! [...] Não esperava porque nunca foi feito pra mim né?! Não esperava, porque nos outros anos não foi feito isso, foi feito esse ano, no dia 13 de novembro. (E10).

Ainda nesse quesito, deparou-se com certa contradição de pensamentos, pois o participante inicia seu pensamento referindo que o atendimento oferecido pela equipe foi bom e no desenvolvimento do raciocínio revela que não reconhece como atendimento as propostas que lhe foram oferecidas.

Pra ser franco o atendimento que elas me prestaram, com essas que são residente, foi muito bom. [...] Não, o que eu posso dizer dessa parte que elas ainda não estão capacitadas pra assistência da saúde. [...] Mas elas não tão prestando atendimento à saúde ainda. [...] Não porque nessa parte ainda tá faltando algo que nem eu não sei mais ou menos descrever. As residente não fizeram servico. Nesse aspecto. De fazer curativo... (E3).

É plausível considerar que os dados acima apresentam significativa assimetria de opiniões diante de uma mesma ação. Tal diferença desencadeou reflexões que circundam o que os usuários consideram como práticas/ações em saúde ou não.

É interessante que, ao ser questionado sobre ações em saúde, um dos participantes reconhece apenas ações ligadas à doença. 
Nesse âmbito, é provável que o conceito de atendimento corrobore a relação apontada por Degani (2008) de que as doenças são passíveis de terapêutica, ou seja, ações aplicadas em corpos individuais, como ingestão de medicamentos e troca de curativo.

Cabe aqui ressaltar ainda como são intrigantes as diferenciadas concepções do processo saúde-doença, considerando que alguns participantes ainda têm seus horizontes fechados para essa questão, enquanto outros parecem ter visões mais ampliadas.

\section{Críticas: o despertar de potências}

No momento de categorizar os dados, notou-se que, em diferentes perguntas, foi encontrado algum grau de crítica por parte dos participantes. Tendo em vista que críticas são ferramentas indispensáveis para o crescimento e construção em saúde, julga-se importante trazê-las para discussão neste trabalho.

Vale destacar que os participantes, ao abordarem $o$ atendimento oferecido pelas equipes multiprofissionais, chegaram a fazer comparações com o atendimento recebido em outros serviços de saúde que não dispõem dessa oferta. É interessante notar que, ao mesmo tempo em que elogiam o atendimento prestado pelas equipes multiprofissionais, justificam os demais serviços pela impossibilidade de ofertar esse tipo de atendimento, alegando a grande demanda como impeditivo:

Às vezes a pessoa quando você vai procurar elas são meio... Não sei se é porque estão ocupadas demais. São meio frias às vezes. [...] Aí as pessoas ficam muito ocupada, às vezes a pessoa quer te atender melhor mas não pode, né?! (E2).

"[...] eu percebo isso mais no fundo no fundo não é nem pra perceber, porque lá tem que ser assim mesmo, porque é uma multidão de gente não é verdade?" (E9).

Nesse ponto, surge uma inquietação ao se pensar se os sujeitos assumem a postura de compreensão ou de certo conformismo por não perceber melhorias. Na verdade, essas diferenças que circundam a apatia e a manutenção de certas cristalizações nas atuações profissionais cotidianas deveriam ser estudadas conforme sugere Degani (2008).

Nesse sentido, a fala abaixo desperta atenção, pois o entrevistado revela certo temor de que os integrantes da equipe multiprofissional, ainda em processo de formação pela residência, mudem sua postura ao serem inseridos no mercado de trabalho.

Tem meninas que é bem aproveitada porque elas têm uma, como é que se diz, uma, uma vontade de... mas vamos vê se vai continua assim né?! A diferença aqui é o seguinte, que elas tão na faculdade, elas amanhã, se elas terminam a residência, aí chega amanhã tem um concurso e elas passam no concurso aí vão fazer a mesma coisa que... (E3).

A forma como o profissional adere ao sistema é uma importante questão que demanda oportunas reflexões, bem como a preocupação referida na fala a seguir de que o residente possa ser influenciado negativamente pelos exemplos vivenciados no serviço. "Ela é acima, ela é acima e os residente que estão ali com ela tomando experiência, orientação, vai acabar seguindo a cabeça dela” (E3).

No corolário dessa questão, destaca-se que o participante, ao expressar que o mau atendimento além de gerar conflitos pode ser perpetuado, revela que sentiu mudança na equipe do serviço após a inserção das equipes multiprofissionais do Programa de Residência, atribuindo a estes profissionais o papel de multiplicadores.

Se você é mal atendido vai gerar briga, vai gerar discussão. Se você é bem atendido, um pouquinho de carinho da pessoa... [...] O corpo de enfermeiro aí, mudou por causa de vocês, eles não eram assim não. Desde a primeira equipe que veio a gente sentiu a mudança deles. Desde a primeira equipe, foi mudando devagarinho. (E8). 
Nesse contexto, Albuquerque (2008) aponta que a articulação entre ensino e serviço pode ser propulsora para mudança de práticas profissionais. Então, acredita-se que os estudantes, ao utilizarem de suas vivências e conhecimentos adquiridos nas práticas em saúde, assumem uma postura que vai além da formação profissional e acabam por contagiar aqueles que trabalham no mesmo ambiente.

Para finalizar, houve interesse em indagar se os sujeitos julgavam interessante que existisse uma equipe como as que os acompanharam em outros serviços de saúde, e neste ponto, a maioria referiu que sim. Nesse contexto, na fala abaixo é expressa a percepção da importância em ter as informações relacionadas à saúde devidamente explicadas e retoma um ponto indicado anteriormente, sobre suposta falta de tempo dos funcionários dos serviços como fator dificultador para tal.

Ah sim, muito, muito mesmo. Devia ter uma equipe assim, eu acho. Porque assim, não é sempre que você chega aqui e você... ninguém... é difícil a pessoa vim te explicar as coisas, porque eles nem têm tempo de explicar nada. (E5).
Indubitavelmente, os serviços de saúde encontram diversas dificuldades no cotidiano de suas atividades, como déficit de recursos humanos e grande demanda, porém tais fatores não justificam as questões apontadas pelos participantes nesta discussão.

\section{Considerações finais}

A partir da apresentação e discussão dos dados, acredita-se que o trabalho em questão atingiu os objetivos propostos e trouxe alguns pontos da visão daqueles que melhor podem revelar a abordagem multiprofissional em saúde: os usuários. Ademais, o material abre frentes de discussão referentes à atenção à saúde.

Aparentemente, a abordagem multiprofissional, com tendência interprofissional, vivenciada pelos sujeitos entrevistados nesta pesquisa envolveu fatores positivos, porém, conforme encontrado na literatura, ainda existem barreiras para a efetivação dessa prática nos serviços de saúde e até na consagração de cursos para essa formação. Nesse âmbito, considera-se importante que mais estudos sejam feitos com o intuito de sugestionar as implicações promovidas por tal forma de trabalho.

\section{Referências}

\footnotetext{
ALBUQUERQUE, V. S. A Integração ensino serviço no contexto do processo de mudança na formação superior dos profissionais de saúde. Revista Brasileira de Educação Médica, Rio de Janeiro, v. 32, n. 3, p. 356-362, 2008.
}

ALVES, V. S. Um modelo de educação em saúde para o Programa Saúde da Família: pela integralidade da atenção e reorientação do modelo assistencial. Interface - Comunicação, Saúde, Educação, Botucatu, v. 9, n. 16, p. 39-52, 2012.
BATISTA, N. A. Educação Interprofissional em Saúde: Concepções e Práticas. Caderno FNEPAS, Rio de Janeiro, v. 2, p. 25-8, 2012.

BRASIL. Lei no 8.080, de 19 de setembro de 1990. Dispões sobre as condições para a promoção, proteção e recuperação da saúde, a organização e o funcionamento dos serviços correspondentes e dá outras providências. Diário Oficial [da] União, Brasília, DF, 20 set. 1990. Disponível em: <http://www. 
planalto.gov.br/ccivil_03/Leis/L8080.htm >. Acesso em: 21 ago. 2015.

Ministério da Saúde. Secretaria de Atenção à Saúde. Núcleo Técnico da Política Nacional de Humanização. Clínica Ampliada e Compartilhada. Brasília, DF: Ministério da Saúde, 2009.

Ministério da Saúde. Secretaria de Atenção à Saúde. Núcleo Técnico da Política Nacional de Humanização. Documento Base para Gestores e Trabalhadores do SUS. Brasília, DF: Ministério da Saúde, 2008. Disponível em: <http://bvsms.saude.gov. br/bvs/publicacoes/humanizasus_gestores_trabalhadores_sus_4ed.pdf $>$. Acesso em: 21 ago. 2015.

Ministério da Saúde. Secretaria de Gestão do Trabalho e da Educação na Saúde. Departamento de Gestão da Educação em Saúde. Residência Multiprofissional em saúde: experiências, avanços e desafios. Brasília, DF: Ministério da Saúde, 2006.

CECCIM, R. B.; FEUERWERKER, L. C. M. O quadrilátero da formação para a área da saúde: ensino, gestão, atenção e controle social. Physis, Rio de Janeiro, v. 14, n. 1, p. 41-65, 2012.

CUNHA, E. M.;GIOVANELLA, L. Longitudinalidade/ continuidade do cuidado: identificando dimensões e variáveis para a avaliação da Atenção Primáriano contexto do sistema público de saúde brasileiro. Ciência \&t Saúde Coletiva, Rio de Janeiro, v. 16, n. 1, p. 1029-42, 2011.

DEGANI, V.C. A resolubilidade dos problemas de saúde: opinião de usuários em uma unidade básica de saúde comunitária. 2008. 197 f. Dissertação (Mestrado em Enfermagem) - Universidade Federal do Rio Grande do Sul, Porto Alegre, 2008

FRANCO JUNIOR, A. J. et al. A importância do vínculo entre equipe e usuário para o profissional da saúde. Investigação, Franca, v. 8, n. 1-3, p. 11-8, 2008 .

FURTADO, J. P. Equipes de referência: arranjo institucional para potencializar a colaboração entre disciplinas e profissões. Interface- Comunicação, Saúde, Educação, Botucatu, 2007, v. 11, n. 22, p. 239-255.

HENZ, A. et al. Trabalho entreprofissional: acerca do comum e a cerca do específico. In: CAPOZZOLO, A. A.; CASETTO, S. J.; HENZ, A. (Org.). Clínica comum: itinerários de uma formação em saúde. São Paulo: Hucitec, 2013. p. 170

MINAYO, M. C. S. O desafio do conhecimento: pesquisa qualitativa em saúde. 9 ed. São Paulo: Hucitec, 2009.

PEDUZZI, M. Equipe multiprofissional em saúde: conceito e tipologia. Revista de Saúde Pública, São Paulo, v. 1, n. 35, p. 103-9, 2011.

Trabalho em equipe de saúde no horizonte normativo da integralidade, do cuidado e da democratização das relações de trabalho. 2007. Disponível em: <http://formsus.datasus.gov.br/ novoimgarq/10973/1488992_134647.pdf >. Acesso em: 30 ago. 2015.

PINHO, M. C. G. Trabalho em equipe de saúde: limites e possibilidades de atuação eficaz. Ciências $\mathcal{E}$ Cognição, Rio de Janeiro, v. 8, p. 68-87, 2006.

POLIT, D. F.; HUNGLER, B. P. Fundamentos de pesquisa em enfermagem. 3 ed. Porto Alegre: Artes Médicas; 2010.

RIBEIRO, V. C. Trabalho em equipes de saúde: uma revisão integrativa. 2015. Monografia (Especialização em Residência Multiprofissional em Atenção à Saúde) - Universidade Federal de São Paulo, Santos, 2015.

SALVADOR, A. S. et al. Construindo a multiprofissionalidade: um olhar sobre a residência multiprofissional em saúde da família e comunidade. Revista Brasileira de Ciências da Saúde, João Pessoa, v. 15, n. 3, p. 329-38, 2011.

Recebido para publicação em junho de 2015

Versão final em setembro de 2015

Conflito de interesses: inexistente

Suporte financeiro: não houve 